\title{
Improving the enrichment procedure for Enterobacteriaceae detection
}

\author{
Christine Weber ${ }^{\mathrm{a}}$, Roger Stephan ${ }^{\mathrm{a}, *}$, Patrick Druggan ${ }^{\mathrm{b}}$, Han Joosten ${ }^{\mathrm{c}}$, Carol Iversen ${ }^{\mathrm{a}, \mathrm{d}}$ \\ ${ }^{a}$ Institute for Food Safety and Hygiene, Vetsuisse Faculty, University of Zurich, Winterthurerstrasse 272, CH-8057 Zurich, Switzerland \\ ${ }^{\mathrm{b}}$ Oxoid Ltd., Thermo Fisher Scientific, Basingstoke, Hampshire RG24 8PW, United Kingdom

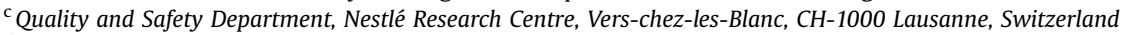 \\ d Centre for Food Safety, School of Agriculture, Food Science and Veterinary Medicine, University College Dublin, Belfield, Dublin 4, Ireland
}

\section{A R T I C L E I N F O}

\section{Article history:}

Received 29 December 2008

Received in revised form

20 March 2009

Accepted 21 March 2009

Available online $\mathrm{xxx}$

\section{Keywords:}

Enterobacteriaceae

Detection

Enrichment

\begin{abstract}
A B S T R A C T
The current ISO standard method for detection of Enterobacteriaceae (21528-1:2004) includes enrichment in EE broth which has been shown to be inhibitory to some members of this family, notably Cronobacter spp. A shortened procedure omitting the EE broth has been proposed, however competition from Gram-positive flora may be detrimental to the effective recovery of low levels of target organisms in some sample matrices. In this study we investigated novel cost effective modifications, designed to improve ISO 21528-1:2004 for the detection of Enterobacteriaceae. Initial experiments used a worse-case scenario involving stressed Enterobacteriaceae strains known to grow poorly in laboratory media as well as representative background competitors from powdered milk. The interaction between the Enterobacteriaceae and their competitors was characterised and additives to enhance the growth of target strains over non-target strains were investigated.

Supplementation of BPW with $40 \mu \mathrm{M}$ 8-hydroxyquinoline, $0.5 \mathrm{~g} \mathrm{~L}^{-1}$ ammonium iron(III) citrate, $0.1 \mathrm{~g} \mathrm{~L}^{-1}$ sodium deoxycholate and $0.1 \mathrm{~g} \mathrm{~L}^{-1}$ sodium pyruvate (BPW-S) improved the recovery of Enterobacteriaceae from artificially and naturally contaminated samples. This improvement of the pre-enrichment broth may also be of interest for methods designed to detect specific foodborne pathogens belonging to the Enterobacteriaceae (e.g. Salmonella spp., Cronobacter spp.) that require a pre-enrichment step in BPW.
\end{abstract}

(c) 2009 Elsevier Ltd. All rights reserved.

\section{Introduction}

The family Enterobacteriaceae are useful indicators for verification of hygiene processes in food production facilities (Anon., 2005). The current ISO standard method 21528-1:2004 (Anon., 2004) comprises pre-enrichment in buffered peptone water (BPW), followed by enrichment in Enterobacteriaceae enrichment (EE) broth, which is then streaked on violet red bile glucose (VRBG) agar. Typical colonies on VRBG are confirmed as Enterobacteriaceae based on negative oxidase activity and positive glucose fermentation.

It has been reported that some potentially pathogenic strains of Enterobacteriaceae do not grow well in EE broth (Gurtler and Beuchat, 2005; Iversen and Forsythe, 2007; Joosten et al., 2008). This challenges the reliability of the results obtained with the current ISO standard as an indicator of poor hygiene, inadequate processing or post-process contamination of foods.

A revision to the ISO standard method (21528-1:2004) has been proposed in which the selective enrichment in EE broth is omitted and samples pre-enriched in BPW are directly plated on VRBG agar

\footnotetext{
* Corresponding author. Tel.: +41 4463586 51; fax: +41 446358908 .

E-mail address: stephanr@safety.uzh.ch (R. Stephan).
}

(Joosten et al., 2008). This method has been shown to give comparable results to ISO 21528-1:2004 and also reduces the test time facilitating quicker release of product. Removal of the selective enrichment in EE broth means that any non-Enterobacteriaceae present in the sample that are able to grow in BPW during pre-enrichment may compete with the Enterobacteriaceae reducing the numbers of target colonies that are transferred onto the VRBG agar. This may be a consideration for matrices that are likely to contain low numbers of stressed Enterobacteriaceae and relatively high numbers of thermoduric spores, such as powdered milk and infant formulae (Murphy et al., 1999).

Bacillus spp. are a genera of Gram-positive rods that produce endospores as a dormant state allowing them to deal with extreme conditions such as high temperatures and desiccation (Nicholson et al., 2000; Huck et al., 2008). The ability to survive these conditions means that Bacillus spp. are frequently found as members of the microflora of powders (Gabis et al., 1970; Anderton, 1986; Antai, 1988; Crielly et al., 1994; Kunene et al., 1999; Rueckert et al., 2005; Ronimus et al., 2006; Reyes et al., 2007). Additionally, some Bacillus spp. produce antimicrobial molecules that are active against Gram-negative organisms such as polymyxin and colistin (Katz and Demain, 1977; He et al., 2007). It has been shown that for some 
samples, such as powdered infant formula, addition of vancomycin to inhibit Gram-positive microflora during the pre-enrichment resulted in a trend for increased recovery of Enterobacteriaceae (Joosten et al., 2007). Vancomycin is heat labile and is an expensive additive given the volumes of pre-enrichment media used. Also concern has been expressed in relation to the possible spread of vancomycin resistance genes (Willems et al., 2005). The compounds 8-hydroxyquinoline and sodium deoxycholate are heat stable and economically viable as possible alternatives to vancomycin. Sodium deoxycholate is a water soluble anionic detergent that is found in the intestine of higher animals (Haselwood, 1967). It is the selective agent in bile salts (Stacey and Webb, 1947; D'Mello and Yotis, 1987) and has been used as an antimicrobial agent in culture media for more than 100 years (MacConkey, 1905). The monoprotic bidentate chelating agent 8-hydroxyquinoline has been used in topical ointments (Tanzer et al., 1978) and as a potential anti-plaque agent in dental washes (Depalma et al., 1975; Tanzer et al., 1978). The activity of 8-hydroxyquinoline against Gram-positive organisms has been reported to be $10-100$ fold higher than against Gram-negative organisms (Albert et al., 1947).

This study investigates novel cost effective modifications, designed to improve ISO 21528-1:2004 for the detection of Enterobacteriaceae. Initial experiments used a worse-case scenario involving stressed Enterobacteriaceae strains known to grow poorly in laboratory media and representative Bacillus spp. from powdered milk. The interaction between the Enterobacteriaceae and their competitors was characterised and additives to enhance the growth of target strains over non-target strains were investigated.

\section{Methods}

\subsection{Bacterial isolates used in this study}

The strains used in this study were obtained from the culture collections at Nestlé Research Centre, Lausanne, Switzerland; the Institute for Food Hygiene and Safety, University of Zurich, Switzerland; the Centre for Food Safety, University College Dublin, Ireland and Oxoid Ltd., Thermo Fisher Scientific, Basingstoke, UK (Table 1). The Enterobacteriaceae strains chosen for the study included 9 strains that had been previously found to be particularly sensitive to selective agents used in microbiological growth media (Joosten et al., 2008). Non-target competitors included 11 strains of Gram-positive cocci and three Bacillus strains from the Nestlé Research Centre culture collection chosen to cover a variety of species, as well as 11 primary isolates of Gram-positive rods obtained from commercially available milk powders (2.2; Table 1 ).

\subsection{Isolation and identification of Gram-positive background flora from powdered milk products}

To provide representative background competitors, 25 g each of 15 different brands of infant formula and 1 skimmed milk powder were pre-enriched overnight at $37{ }^{\circ} \mathrm{C}$ in $225 \mathrm{ml}$ BPW (Oxoid, UK). After pre-enrichment, samples were streaked $(10 \mu \mathrm{l})$ onto tryptone soya agar (TSA) and incubated overnight at $37^{\circ} \mathrm{C}$. Recovered Gram-positive strains were further characterised using $\mathrm{API}^{\circledR} 50$ CHB test galleries (bioMérieux, France) and by 16S rRNA gene sequencing (Fasteris SA, Switzerland).

\subsection{Inhibitory interactions between Gram-positive strains and Enterobacteriaceae}

Inhibitory interactions between the isolated Gram-positive strains and Enterobacteriaceae strains were investigated using deferred-direct cross-streaking assays on TSA and infant formula
Table 1

Strains used in this study.

\begin{tabular}{|c|c|c|c|}
\hline Strain & Identification & & Origin \\
\hline \multicolumn{4}{|c|}{ Gram-positive rods } \\
\hline Bc1 & Bacillus flexus & & Infant formula ${ }^{a}$ \\
\hline Bc3 & Bacillus thuringiensis & & Infant formula ${ }^{a}$ \\
\hline Bc5 & no type strain match & & Infant formula ${ }^{a}$ \\
\hline Bc7 & no type strain match & & Infant formula ${ }^{a}$ \\
\hline Вс9 & no type strain match & & Infant formula ${ }^{a}$ \\
\hline Bc11 & no type strain match & & Infant formula ${ }^{a}$ \\
\hline $\mathrm{Bc} 12 \mathrm{a}$ & Bacillus subtilis & & Infant formula ${ }^{a}$ \\
\hline $\mathrm{Bc} 12 \mathrm{~b}$ & no type strain match & & Infant formula ${ }^{a}$ \\
\hline Bc13 & Bacillus subtilis & & Infant formula ${ }^{a}$ \\
\hline Bc14 & Bacillus velezensis & & Infant formula ${ }^{a}$ \\
\hline $\mathrm{BcHP}$ & no type strain match & & Milk powder ${ }^{\mathrm{a}}$ \\
\hline B44 & Bacillus cereus & ATCC 33019 & Infant formula \\
\hline B152 & Bacillus subtilis & & Condensed milk \\
\hline B162 & Bacillus mycoides & & Milk \\
\hline \multicolumn{4}{|c|}{ Gram-positive cocci } \\
\hline STA108 & Staphylococcus aureus & & Unknown \\
\hline STA201 & Staphylococcus auricularis & ATCC 33753 & Ear \\
\hline STA209 & Staphylococcus sciuri & DSM 20345 & Squirrel skin \\
\hline STA241 & Staphylococcus saprophyticus & DSM 20229 & Urine \\
\hline STA242 & Staphylococcus cohnii & DSM 20260 & Human skin \\
\hline STA247 & Staphylococcus saprophyticus & & Unknown \\
\hline STA313 & Staphylococcus epidermidis & ATCC 9491 & Unknown \\
\hline STR45 & Enterococcus faecalis & & Unknown \\
\hline STR48 & Enterococcus faecium & & Unknown \\
\hline STR70 & Enterococcus durans & & Unknown \\
\hline STR73 & Streptococcus agalactiae & ATCC49446 & Neonatal sepsis \\
\hline \multicolumn{4}{|c|}{ Enterobacteriaceae } \\
\hline LMG $23827^{\mathrm{T}}$ & Cronobacter turicensis & & Neonatal meningitis ${ }^{\mathrm{b}}$ \\
\hline LMG $23823^{\mathrm{T}}$ & Cronobacter dublinensis & & Factory environment ${ }^{c}$ \\
\hline E532 & Cronobacter malonaticus & & Clinical isolate \\
\hline E539 & Cronobacter sakazakii & & Clinical isolate \\
\hline E540 & Cronobacter sakazakii & & Clinical isolate \\
\hline ATCC $29544^{\mathrm{T}}$ & Cronobacter sakazakii & & Child's throat \\
\hline ATCC 12868 & Cronobacter sakazakii & & Unknown \\
\hline ATCC $51329^{\mathrm{T}}$ & Cronobacter muytjensii & & Unknown \\
\hline E604 & Cronobacter sakazakii & & Clinical isolate \\
\hline E617 & Enterobacter amnigenus & & Food \\
\hline E632 & Cronobacter sakazakii & & Infant food \\
\hline E655 & Cronobacter sakazakii & & Clinical isolate \\
\hline E770 & Cronobacter sakazakii & & Milk powder \\
\hline NCTC 9529 & Cronobacter genomosp. 1 & & Water \\
\hline LMG $23826^{\mathrm{T}}$ & Cronobacter malonaticus & CDC-1058-77 & Clinical isolate \\
\hline E827 & Cronobacter sakazakii & CDC 407-77 & Clinical isolate \\
\hline E934 & Cronobacter sakazakii & & Rice flour \\
\hline OCC 118 & Enterobacter cloacae & & Unknown $^{\mathrm{d}}$ \\
\hline OCC 2758 & Citrobacter sp. & & Unknown $^{\mathrm{d}}$ \\
\hline
\end{tabular}

a Primary isolates from powdered milk and formula.

b From the culture collection at the Institute for Food Hygiene and Safety, University of Zurich, Switzerland.

From the culture collection at the Centre for Food Safety, University College Dublin, Ireland.

d From the culture collection at Oxoid Ltd., Thermo Fisher Scientific, Basingstoke, UK; all other isolates were obtained from the culture collection at Nestlé Research Centre, Lausanne, Switzerland.

milk agar (IFMA, comprising $200 \mathrm{ml}$ infant formula, $0.4 \mathrm{~g}$ ammonium sulphate, $3 \mathrm{~g}$ agar and $40 \mathrm{ml}$ distilled water). Gram-positive strains were streaked as single lines across agar plates using a swab and incubated overnight at $30^{\circ} \mathrm{C}$. The visible growth was removed using a sterile spatula or swab and, to suppress remaining viability of the Gram-positive organisms, the plates were treated with exposure to UV $\left(60 \mathrm{~min}\right.$ at $8 \mathrm{~mW} \mathrm{~cm}^{-2}$, i.e. $\left.2880 \mathrm{~J} \mathrm{~m}^{-2}\right)$ and/or chloroform applied directly the agar surface ( $5 \mathrm{ml}$ per plate) for 10 min before evaporation in a fume hood. The Enterobacteriaceae strains were then streaked as single lines at $90^{\circ}$ to the previous Gram-positive growth, the plates were incubated overnight and the growth of the Enterobacteriaceae observed. Growth inhibition around the junctions of the bacterial streaks indicated the possible 
presence of inhibitory compounds produced by prior growth of Gram-positive organisms. Growth of Enterobacteriaceae on the area of TSA and IFMA that had no previous growth of Gram-positive strains acted as an internal control for each plate indicating that any observed inhibition was not due to residual chloroform. Additionally, cell-free supernatants from strains BcHP, Bc14, ATCC $29544^{\mathrm{T}}$ and E632 (Table 1) grown overnight in brain heart infusion (BHI, Oxoid, UK) were two-fold serially diluted and the ability to suppress growth of competing strains assessed by measuring the time-to-detection (TTD) in a Bioscreen C (Thermofisher, UK).

\subsection{Comparing growth rate in skimmed milk and infant formula}

The growth rate in UHT skimmed milk (Migros) and UHT infant formula (HiPP) of two Cronobacter sakazakii strains (ATCC $29544^{\mathrm{T}}$ and E632) was determined in both pure culture and in the presence of Gram-positive competitors. For each media sterile ready-to-use brands were used of which $250 \mathrm{ml}$ was inoculated with $0.1 \mathrm{ml}$ of approximately $1 \times 10^{5} \mathrm{CFU} \mathrm{ml}^{-1}$ of the test strain(s) grown overnight in $\mathrm{BHI}$ and diluted in $0.9 \%$ saline. The inoculated samples were incubated at $37^{\circ} \mathrm{C}$ and $100 \mu \mathrm{l}$ aliquots removed every hour over a period of $24 \mathrm{~h}$. At each time point the sample was decimally diluted in $0.9 \%$ saline to $10^{-8}$ and plate counts performed using the Miles and Misra method (Miles et al., 1938). Plate count agar (PCA, Oxoid, UK) was used to count the Gram-positive species, which were morphologically distinguishable from the Enterobacteriaceae, and TSA containing $10 \mathrm{mg} \mathrm{L}^{-1}$ vancomycin hydrochloride (TSA-V) to inhibit growth of Gram-positive strains was used to count the Enterobacteriaceae.

\subsection{Heat stability of vancomycin hydrochloride}

The effect of heat on the activity of vancomycin hydrochloride was investigated using two-fold serial dilutions in BPW. Initially separate preparations of BPW containing $0.04 \mathrm{~g} \mathrm{~L}^{-1}$ vancomycin were: i) autoclaved at $121^{\circ} \mathrm{C}$ for $15 \mathrm{~min}$, ii) autoclaved at $115^{\circ} \mathrm{C}$ for $15 \mathrm{~min}$ and iii) heated at $100^{\circ} \mathrm{C}$ for $30 \mathrm{~min}$. Additionally, filtersterilised vancomycin (final concentration of $0.04 \mathrm{~g} \mathrm{~L}^{-1}$ ) was added to BPW which had been previously autoclaved at $121^{\circ} \mathrm{C}$ for $15 \mathrm{~min}$. The BPW-vancomycin preparations were serially diluted in 96-well microtitre plates $(100 \mu \mathrm{l}$ per well) and $100 \mu \mathrm{l}$ of approximately $1 \times 10^{5} \mathrm{CFU} \mathrm{ml}^{-1}$ of the test strains (Table 1 ), which had been grown overnight in BHI and decimally diluted in BPW, were added. The final concentrations of vancomycin ranged from $0.02 \mathrm{~g} \mathrm{~L}^{-1}$ to $0.0003 \mathrm{~g} \mathrm{~L}^{-1}$. The optical density $\left(\mathrm{OD}_{600 \mathrm{~nm}}\right)$ of the wells was read at $0 \mathrm{~h}$ and after incubation for $24 \mathrm{~h}$ at $37^{\circ} \mathrm{C}$ using a Sunrise ${ }^{\mathrm{TM}}$ microplate reader (Tecan Group Ltd., Switzerland). The percentage change in $\mathrm{OD}_{600 \mathrm{~nm}}$ was plotted against vancomycin concentration and the relative activity of the BPW-vancomycin preparations compared.

\subsection{Optimization of pre-enrichment medium: inhibition of Gram-positive organisms}

Alternative antimicrobial agents were assessed in comparison to vancomycin. BPW supplemented with sodium deoxycholate was prepared by adding $1.0 \mathrm{~g} \mathrm{~L}^{-1}$ sodium deoxycholate (Sigma) to BPW prior to autoclaving at $121^{\circ} \mathrm{C}$ for $15 \mathrm{~min}$. The BPW-sodium deoxycholate was then diluted to give final concentrations of $0.05,0.1$, $0.2,0.25,0.3,0.4$ and $0.5 \mathrm{~g} \mathrm{~L}^{-1}$ sodium deoxycholate after $100 \mu \mathrm{l}$ of $2 \times$ dilution was dispensed into the wells of one row in the 96-well plate and inoculated with $100 \mu \mathrm{l}$ of culture as above.

BPW supplemented with 8-hydroxyquinoline was prepared by adding $100 \mathrm{mM}$ 8-hydroxyquinoline (Sigma) to BPW prior to autoclaving at $121^{\circ} \mathrm{C}$ for $15 \mathrm{~min}$. The BPW-8-hydroxyquinoline was then diluted and inoculated as above to give final concentrations of
$10,20,30,40,50,60,70,80,90,100$ and $200 \mu \mathrm{M}$ 8-hydroxyquinoline in the wells.

The $\mathrm{OD}_{600 \mathrm{~nm}}$ of the plates was read at $0 \mathrm{~h}$ and $24 \mathrm{~h}$ as above. Inhibition of strains was compared by determining the concentrations that resulted in a reduction of greater than $50 \%$ of the final $\mathrm{OD}_{600 \mathrm{~nm}}$.

\subsection{Optimization of pre-enrichment medium: addition of ammonium iron(III) citrate and pyruvate}

Aliquots of UHT skimmed milk $(10 \mathrm{ml})$ were either supplemented with ammonium iron(III) citrate $\left(0.5 \mathrm{~g} \mathrm{~L}^{-1}\right)$ or sodium pyruvate $\left(0.1 \mathrm{~g} \mathrm{~L}^{-1}\right)$. The preparations were then inoculated with C. sakazakii strain ATCC $29544^{\mathrm{T}}$ or E632 with and without Bc14 and BcHP. The samples were incubated at $37^{\circ} \mathrm{C}$ for $24 \mathrm{~h}$ and $100 \mu \mathrm{l}$ aliquots removed at 0 and $24 \mathrm{~h}$. At each time point the samples were decimally diluted in $0.9 \%$ saline to $10^{-8}$ and plate counts performed. The Gram-positive species were counted on TSA and the Enterobacteriaceae were counted on TSA-V.

\subsection{Optimization of pre-enrichment medium: efficacy of 8-hydroxyquinoline in milk with and without ammonium iron(III) citrate}

Aliquots ( $10 \mathrm{ml}$ ) of UHT skimmed milk and infant formula were supplemented with 8-hydroxyquinoline to final concentrations of $0,40,60$ and $100 \mu \mathrm{M}$ both with and without ammonium iron(III) citrate $\left(0.5 \mathrm{~g} \mathrm{~L}^{-1}\right)$. The preparations were then inoculated with either C. sakazakii strains ATCC $29544^{\mathrm{T}}$, E632, or E539, or with Bacillus strain Bc14. The samples were incubated at $37^{\circ} \mathrm{C}$ for $24 \mathrm{~h}$ and $100 \mu \mathrm{l}$ aliquots removed at 0 and $24 \mathrm{~h}$. At each time point the samples were decimally diluted in $0.9 \%$ saline to $10^{-8}$ and plate counts performed. The Bc14 strain was counted on TSA and the Cronobacter were counted on TSA-V.

\subsection{Optimization of pre-enrichment medium: recovery of desiccated cells}

Ten Gram-positive isolates (Bc1, Bc12a, Bc13, Bc14, BcHP, STA209, STA241, STA247, STR45 and STR70) and six Enterobacteriaceae strains (E539, ATCC 29544 ${ }^{\mathrm{T}}$, E604, E617, E632 and E827) were grown overnight in BPW at $37^{\circ} \mathrm{C}$. For each strain aliquots of $10 \mu$ l (approximately $10^{7} \mathrm{CFU}$ ) were placed into wells of Bioscreen $\mathrm{C}$ plates $(n=5$ for each rehydration broth). The plates were dried for $4 \mathrm{~h}$ in a sterile cabinet and then stored for one week in the dark in a sealed box containing Drierite ${ }^{\circledR}$ (Sigma) to standardize the relative humidity. The dried cells were rehydrated with $400 \mu \mathrm{l}$ per well of the following media: 1) BPW; 2) BPW plus $40 \mu \mathrm{M}$ 8-hydroxyquinoline; 3) BPW plus $0.1 \mathrm{~g} \mathrm{~L}^{-1}$ sodium deoxycholate; 4) BPW plus $10 \mathrm{mg} \mathrm{L}^{-1}$ vancomycin; 5) BPW plus $40 \mu \mathrm{M}$ 8-hydroxyquinoline plus $0.5 \mathrm{~g} \mathrm{~L}^{-1}$ ammonium iron(III) citrate; 6 ) BPW plus $40 \mu \mathrm{M}$ 8-hydroxyquinoline plus $0.1 \mathrm{~g} \mathrm{~L}^{-1}$ sodium deoxycholate; 7) BPW plus $40 \mu \mathrm{M}$ 8-hydroxyquinoline plus $0.5 \mathrm{~g} \mathrm{~L}^{-1}$ ammonium iron(III) citrate plus $0.1 \mathrm{~g} \mathrm{~L}^{-1}$ sodium deoxycholate; 8) BPW plus $40 \mu \mathrm{M}$ 8-hydroxyquinoline plus $0.5 \mathrm{~g} \mathrm{~L}^{-1}$ ammonium iron(III) citrate plus $0.1 \mathrm{~g} \mathrm{~L}^{-1}$ sodium deoxycholate plus $0.1 \mathrm{gL}^{-1}$ sodium pyruvate; 9) BPW plus $0.5 \mathrm{~g} \mathrm{~L}^{-1}$ ammonium iron(III) citrate; 10 ) BPW plus $0.1 \mathrm{~g} \mathrm{~L}^{-1}$ sodium pyruvate. Immediately after rehydration the $\mathrm{OD}_{600 \mathrm{~nm}}$ of the wells was read every 15 min over $24 \mathrm{~h}$ using the Bioscreen $C$. The overall change in OD was calculated as the maximum $\mathrm{OD}_{600 \mathrm{~nm}}$ reading minus the initial background $\mathrm{OD}_{600 \mathrm{~nm}}$ reading. The time-to-detection (TTD) was calculated as the time taken for the $\mathrm{OD}_{600 \mathrm{~nm}}$ to increase to a value greater than twice that of the initial background $\mathrm{OD}_{600 \mathrm{~nm}}$ reading. The relative performance of the rehydration broths was calculated as $\Delta \mathrm{OD}_{600 \mathrm{~nm}} / \mathrm{TTD}$. 
Additionally, the relative recovery of strains desiccated in milk using different pre-enrichment broths was compared. Gram-positive strains and Enterobacteriaceae strains (Table 1) were grown overnight in BHI, $10 \mathrm{ml}$ of the cultures were centrifuged at $10000 \mathrm{~g}$ for $10 \mathrm{~min}$ and the supernatant discarded. The cell pellet was resuspended in $1 \mathrm{ml}$ of sterile UHT infant formula and the cell suspension diluted in infant formula to give concentrations of approximately $1 \times 10^{10}$ to $1 \times 10^{0} \mathrm{CFU} \mathrm{ml}^{-1}$. A $10 \mu \mathrm{l}$ aliquot of each dilution was dispensed into the 8 wells of individual columns in a 96-well microtitre plate. The plates were dried for $4 \mathrm{~h}$ in a sterile cabinet then stored for 2 months in the dark in a sealed box containing Drierite ${ }^{\circledR}$ (Sigma). The dried cells were rehydrated with $200 \mu$ l per well of media as described above in preparations $1-8$. The plates were incubated overnight at $37^{\circ} \mathrm{C}$ and, using a 96-pin replicator, approximately $1-3 \mu$ l were transferred to a 96-well plate containing $200 \mu$ indicator medium (comprising TSA with $0.04 \mathrm{~g} \mathrm{~L}^{-1}$ bromocresol purple and $10 \mathrm{~g} \mathrm{~L}^{-1}$ glucose). The indicator plates were incubated at $37^{\circ} \mathrm{C}$ overnight and the number of wells in each column positive for growth and glucose fermentation was recorded. Adjusting appropriately for the dilution factors, the MPN was calculated using the Bacteriological Analytical Manual Online MPN tables (available at http://www.cfsan.fda.gov/ ebam/bam-a2.html; accessed 19-10-2008).

\subsection{Comparison of methods for recovery of Enterobacteriaceae from artificially inoculated samples}

The optimum modified BPW supplemented with $40 \mu \mathrm{M}$ 8-hydroxyquinoline, $0.5 \mathrm{~g} \mathrm{~L}^{-1}$ ammonium iron(III) citrate, $0.1 \mathrm{~g} \mathrm{~L}^{-1}$ sodium deoxycholate and $0.1 \mathrm{~g} \mathrm{~L}^{-1}$ sodium pyruvate (BPW-S) was chosen based on the rehydration experiments above. This was then compared to ISO 21528-1:2004 with and without EE broth as well as to rehydration with BPW containing $10 \mathrm{mg} \mathrm{L}^{-1}$ vancomycin (BPW-V).

To prepare the artificial inoculum, skimmed milk from a local commercial retailer was concentrated to $29 \%$ solids using a climbing film evaporator drawing a -0.95 bar vacuum. Microbial cultures of the following Enterobacteriaceae strains (LMG 23827T, LMG 23823T, ATCC 29544T, ATCC 12868, ATCC 51329T, E604, E632, NCTC 9529, LMG 23826T, E934, OCC 118 and OCC 2758) were grown overnight at $37^{\circ} \mathrm{C}$ in Nutrient broth No. 2 (Thermo Fisher Scientific, UK). The microbial cultures were inoculated into separate $400 \mathrm{ml}$ aliquots of the evaporated milk at a ratio of $1: 100$, to give a final concentration of approximately $1 \times 10^{3} \mathrm{CFU} / \mathrm{ml}$. The solutions were then spray dried using a Lab-Plant SD-04 (Lab-Plant Ltd., UK.) with the outlet temperature set at $150{ }^{\circ} \mathrm{C}$. The spray-drier was decontaminated between each organism using a $1 \%$ sodium hydroxide solution and the cleaning was validated by swabbing the equipment and observing for growth on TSA and DFI agar plates after overnight incubation. The concentration of Enterobacteriaceae in the spraydried powders was determined using an MPN method which involved the rehydration of triplicate $10 \mathrm{~g}, 1 \mathrm{~g}$ and $0.1 \mathrm{~g}$ aliquots in $\mathrm{BPW}$ and incubation overnight at $37^{\circ} \mathrm{C}$. The BPW was sampled with a $10 \mu 1$ loop and streaked on to DFI agar. The inoculation powders were diluted by mixing with commercial powdered milk to give approximately $1 \mathrm{CFU} / \mathrm{g}$ of spray-dried Enterobacteriaceae.

Test samples were prepared using 5-10 g aliquots of the inoculation powder samples made up to $25 \mathrm{~g}$ using skimmed milk powder. Triplicate $25 \mathrm{~g}$ aliquots were subsequently rehydrated using $225 \mathrm{ml}$ of BPW, BPW-V, and BPW-S. All the rehydrated samples were incubated at $37^{\circ} \mathrm{C}$ for $18 \pm 2 \mathrm{~h}$ after which plate counts were performed on VRBGA and TSA-V. Also, $1 \mathrm{ml}$ of the BPW rehydrated samples was transferred to $10 \mathrm{ml}$ EE broth and incubated at $37^{\circ} \mathrm{C}$ for $24 \pm 2 \mathrm{~h}$ before plate counts on VRBGA and TSA-V. The plate count media was incubated at $37^{\circ} \mathrm{C}$ for $24 \pm 2 \mathrm{~h}$ and the colonies identified as Enterobacteriaceae based on the oxidase test and fermentation of glucose.

\subsection{Comparison of methods for recovery of Enterobacteriaceae from naturally contaminated samples}

Ninety-seven different food and environmental matrices were obtained from three different companies. These comprised 29 infant formula products; 5 infant foods; 3 confectionary products; 13 flour/starch/semolina/grain samples; 4 milk proteins; 9 sugar/ syrup samples; 4 cocoa powders; 5 malt drinks; 4 vegetable powders; 2 fruit powders; 1 roasted nut sample; 1 vanilla flavouring sample; 2 vitamin/mineral mixes; and 15 environmental samples from production facilities. The samples were divided into $6 \times 25 \mathrm{~g}$ aliquots; three aliquots were diluted 1:10 in BPW and three were diluted 1:10 in BPW-S. The rehydrated samples were incubated at $37{ }^{\circ} \mathrm{C}$ for $18 \pm 2 \mathrm{~h}$ and plate counts performed on PCA and VRBGA to detect Gram-positive background flora and Enterobacteriaceae respectively. Also, $1 \mathrm{ml}$ of the BPW rehydrated samples was transferred to $10 \mathrm{ml} \mathrm{EE}$ broth, incubated at $37{ }^{\circ} \mathrm{C}$ for $24 \pm 2 \mathrm{~h}$ and plate counts performed. In all cases, the plate count media was incubated at $37^{\circ} \mathrm{C}$ for $24 \pm 2 \mathrm{~h}$ and the colonies identified as Enterobacteriaceae based on the oxidase test and fermentation of glucose. Each sample was tested in triplicate using all three methods.

\section{Results}

\subsection{The influence of Gram-positive background flora on the growth of Enterobacteriaceae}

A total of 11 Bacillus strains were isolated from the milk powder and infant formula samples. The identification results are given in Table 1. The cross-streaking assays on TSA and IFMA indicated that prior growth of strain Bc14 was inhibitory to the growth of some Enterobacteriaceae, particularly E632, whereas the prior growth of $\mathrm{BcHP}$ was not. In the Bioscreen C assays using cell-free supernatants the TTD for E632 was $7.25 \mathrm{~h}$ in BPW with and without the presence of BcHP filtrate, however the TTD increased to $10.5 \mathrm{~h}$ in the presence of Bc14 filtrate. The TTD for ATCC $29544^{\mathrm{T}}$ was $5 \mathrm{~h}$ in all experiments (data not shown).

The growth rate of C. sakazakii strain ATCC $29544^{\mathrm{T}}$ was the same in skimmed milk and in infant formula and was not affected by the presence of BcHP. The growth rate of strain E632 was slower than that of ATCC $29544^{\mathrm{T}}$ in infant formula, and in skimmed milk growth of E632 was not detected without the presence of BcHP. In both growth media, E632 only reached a comparable final concentration to ATCC $29544^{\mathrm{T}}$ when BcHP was present. Additionally, in the presence of ATCC $29544^{\mathrm{T}}$, strain Bc14 was not recovered whereas the growth of strain BcHP was not affected (data not shown).

\subsection{Optimization of pre-enrichment medium: inhibition of Gram-positive organisms}

The addition of sterile solutions of vancomycin did not inhibit the growth of the Enterobacteriaceae at $40 \mathrm{mg} \mathrm{L}^{-1}$. Autoclaving vancomycin solutions at $115^{\circ} \mathrm{C}$ or $121^{\circ} \mathrm{C}$ for 15 min reduced their activity against Gram-positive organisms. All BPW-vancomycin preparations with a final concentration equivalent to $10 \mathrm{mg} \mathrm{L}^{-1}$ were able to inhibit the growth of Gram-positive organisms. No reduction in activity was seen for vancomycin solutions boiled for $30 \mathrm{~min}$ when compared to a filter-sterilised solution (data not shown).

An increase in $\mathrm{OD}_{600 \mathrm{~nm}}$ was not detected for any of the Gram-positive strains in the presence of an 8-hydroxyquinoline concentration of $10 \mu \mathrm{M}$ or above. The effect of 8-hydroxyquinoline on Enterobacteriaceae strains was variable with most strains uninhibited below $100 \mu \mathrm{M}$. Strains E540, E604, E617 and E827 were inhibited between 60 and $80 \mu \mathrm{M}$ and one strain, E539, showed growth inhibition at $30 \mu \mathrm{M}$ (data not shown). 
The growth of the majority of the Staphylococcus and Bacillus strains was reduced by sodium deoxycholate at $0.1 \mathrm{~g} \mathrm{~L}^{-1}$ with no growth detected at concentrations $>0.3 \mathrm{~g} \mathrm{~L}^{-1}$. The growth of strains STA241 and STA209 was reduced at $0.3 \mathrm{~g} \mathrm{~L}^{-1}$ and no growth was detected at concentrations of 0.4 and $0.5 \mathrm{~g} \mathrm{~L}^{-1}$ respectively. The Enterococcus strains appeared to be unaffected by the sodium deoxycholate at the concentrations used. Growth occurred for all of the Enterobacteriaceae at all concentrations of sodium deoxycholate, however, at concentrations $\geq 0.2 \mathrm{~g} \mathrm{~L}^{-1}$ strains E540, E632, E770 and E827 displayed reduced growth with the increase in $\mathrm{OD}_{600 \mathrm{~nm}}$ only reaching $20-40 \%$ of the values obtained in BPW alone (data not shown).

\subsection{Optimization of pre-enrichment medium: addition of ammonium iron(III) citrate}

When grown in infant formula and skimmed milk with and without the additions of 8-hydroxyquinoline and ammonium iron(III) citrate the final CFU ml ${ }^{-1}$ obtained for strain ATCC $29544^{\mathrm{T}}$ was comparable across all experimental conditions. Strain E632 could not be recovered from skimmed milk without the addition of ammonium iron(III) citrate. Also, strain E539 grew poorly in skimmed milk supplemented with 8-hydroxyquinoline alone, reaching only approximately $10^{2} \mathrm{CFU} \mathrm{ml}^{-1}$. When ammonium iron(III) citrate was added to skimmed milk along with 8-hydroxyquinoline the recovery of E632 and E539 improved to final CFU ml ${ }^{-1}$ concentrations comparable to that obtained when these strains were grown in infant formula. Strain Bc14 grew better in infant formula than in skimmed milk reaching concentrations of approximately $10^{8}$ and $10^{4} \mathrm{CFU} \mathrm{ml}^{-1}$ respectively in these media. In infant formula no growth was detected for Bc14 in the presence of 8-hydroxyquinoline. In skimmed milk no growth was detected in the presence of 8-hydroxyquinoline when ammonium iron(III) citrate was also present. When supplemented with 8-hydroxyquinoline alone growth was detected in the presence of 40 and $60 \mu \mathrm{M}$ but not $100 \mu \mathrm{M}$ of this compound. The addition of ammonium iron(III) citrate to infant formula did not appear to affect the recovery of Enterobacteriaceae strains or to improve their growth (Fig. 1).

\subsection{Optimization of pre-enrichment medium: recovery of desiccated cells}

When desiccated cells were rehydrated using BPW supplemented with 8-hydroxyquinoline and sodium deoxycholate either alone or in combination no Gram-positive strains were recovered. However these media also failed to recover all of the Enterobacteriaceae strains. Addition of ammonium iron(III) citrate and/or sodium pyruvate improved recovery of strains. Rehydration of desiccated cells using BPW-S (BPW supplemented with $40 \mu \mathrm{M}$ 8-hydroxyquinoline, $0.5 \mathrm{~g} \mathrm{~L}^{-1}$ ammonium iron(III) citrate, $0.1 \mathrm{~g} \mathrm{~L}^{-1}$ sodium deoxycholate and $0.1 \mathrm{~g} \mathrm{~L}^{-1}$ sodium pyruvate) was determined to give the best recovery of Enterobacteriaceae while inhibiting the growth of Grampositive organisms. All Enterobacteriaceae desiccated in milk were recovered at $\geq 10^{5} \mathrm{MPN} \mathrm{ml}^{-1}$ using this medium with the majority of strains recovered at $\geq 10^{8} \mathrm{MPN} \mathrm{ml}^{-1}$. Recovery of Gram-positive strains ranged from $10^{3}$ to $10^{10} \mathrm{MPN} \mathrm{ml}^{-1}$ in BPW alone, however, using BPW-S no Gram positives were recovered at $\geq 10^{3} \mathrm{MPN} \mathrm{ml}^{-1}$ (data not shown).

\subsection{Comparison of methods for recovery of Enterobacteriaceae from artificially inoculated and naturally contaminated samples}

When powdered milk samples were artificially inoculated with lyophilised strains and recovered using the different methods, the BPW-S enrichment method resulted in consistently higher $\mathrm{CFU} \mathrm{m}{ }^{-1}$ for the Enterobacteriaceae strains than the ISO 21528 and shortened methods. The final concentration of target cells was $>10^{5} \mathrm{CFU} \mathrm{ml}^{-1}$ for all of the Enterobacteriaceae strains using BPW-S

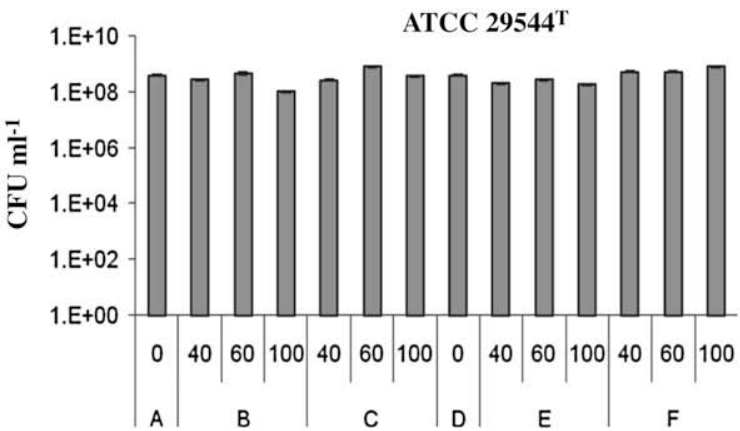

Concentration of 8-hydroxyquinoline $(\mu \mathrm{M})$

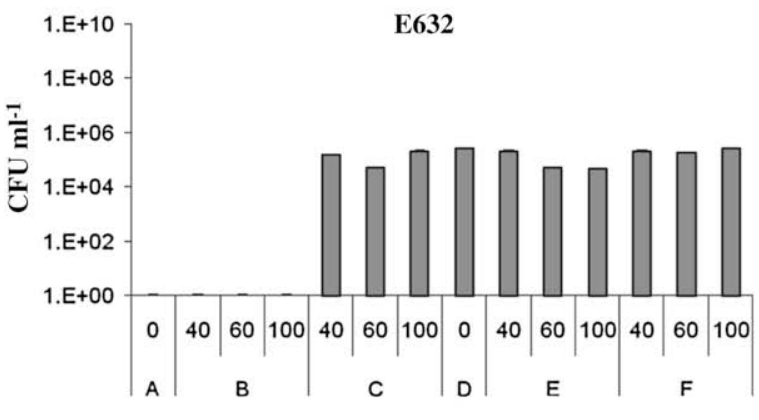

Concentration of 8-hydroxyquinoline $(\mu \mathrm{M})$

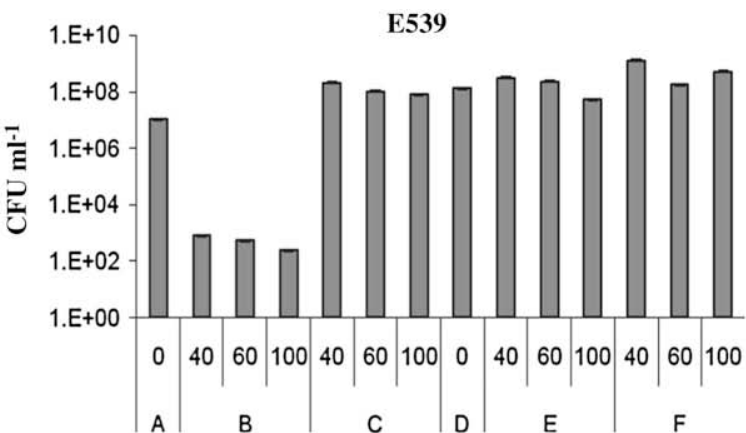

Concentration of 8-hydroxyquinoline $(\mu \mathrm{M})$

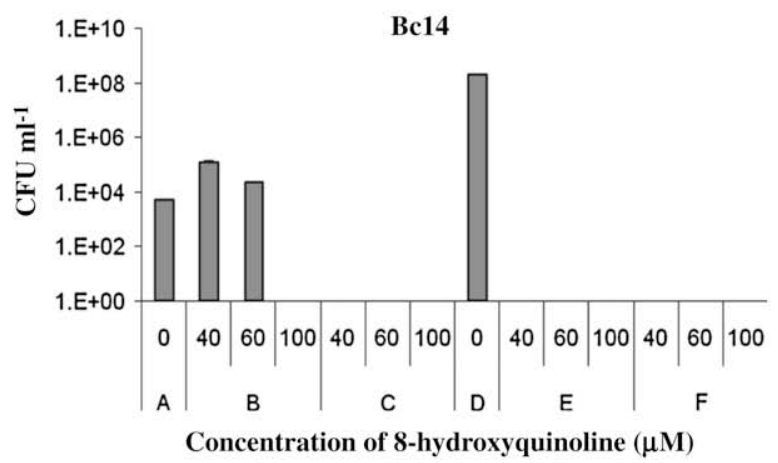

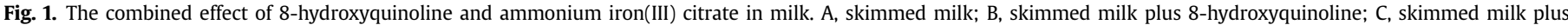

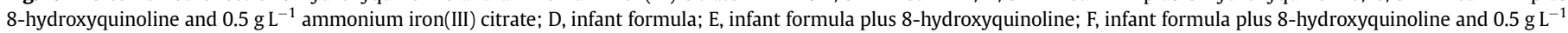
ammonium iron(III) citrate. Strains ATCC $29544^{\mathrm{T}}$, E539 and E 632 are Cronobacter sakazakii; strain Bc14 is Bacillus velezensis. 
with a mean $\log _{10} \mathrm{CFU} \mathrm{m}{ }^{-1}$ of 7.5 compared to $6.3,5.0$ and 6.9 mean $\log _{10} \mathrm{CFU} \mathrm{ml}{ }^{-1}$ for the other methods (Table 2). Using a twosample student $t$-test assuming unequal variances there was a significant difference $(P=0.045)$ between the ISO 21528 and the BPW-S methods; no significant differences were found between ISO 21528 and the other two methods for this data set of artificially contaminated samples.

A total of 291 samples were tested from the 97 food and environmental matrices with the three methods (Table 3). Enterobacteriaceae were recovered from 106 samples after enrichment in BPW-S compared to 91 and 87 positive samples found using ISO 21528 and the shortened procedure respectively, however, using a two-sample student $t$-test assuming unequal variances, the differences between ISO 21528 and the other methods were not significant for this data set of naturally contaminated matrices.

\section{Discussion}

The family Enterobacteriaceae are useful indicators for verification of hygiene processes in food production facilities (Anon., 2005). A revision to the ISO standard method (21528-1:2004) has been proposed in which the selective enrichment in EE broth is omitted and samples pre-enriched in BPW are directly plated on VRBG agar (Joosten et al., 2008). Non-target organisms present in the sample may compete with the Enterobacteriaceae during preenrichment. This is of particular concern for milk powders which often contain thermoduric spores in excess of the levels of Enterobacteriaceae (Murphy et al., 1999). This study investigates novel cost effective modifications, designed to improve ISO 21528-1:2004 for the detection of Enterobacteriaceae.

The Gram-positive rods chosen for this study were isolated from milk products to ensure representative background organisms were used as competitive flora during development and assessment of the method. To provide a worst case scenario, the choice of target strains was directed to isolates previously shown to be sensitive to selective agents included in media commonly used for the recovery of Enterobacteriaceae. Cronobacter spp. (Enterobacter sakazakii) have been shown to be more sensitive to antibiotics than related Enterobacteriaceae (Stock and Wiedemann, 2002) and sensitivity of several isolates to dyes and/or bile salts has been reported (Joosten et al., 2008). The interaction between the Gram-positive strains and the target Enterobacteriaceae appeared complex with certain Bacillus

Table 2

Recovery of lyophilised Enterobacteriaceae from artificially contaminated milk powder.

\begin{tabular}{|c|c|c|c|c|}
\hline \multirow[t]{2}{*}{ Strain } & \multicolumn{4}{|c|}{$\begin{array}{l}\text { Recovery of Enterobacteriaceae using the different methods } \\
\left(\log _{10} \text { CFU ml }{ }^{-1}\right)\end{array}$} \\
\hline & ISO 21528 & Short method $^{\mathrm{a}}$ & BPW-vancomycin ${ }^{\mathrm{b}}$ & $\overline{B P W-S^{c}}$ \\
\hline$\overline{\text { ATCC } 12868}$ & 6.0 & 0.0 & 6.9 & 8.3 \\
\hline ATCC $29544^{\mathrm{T}}$ & 6.3 & 4.9 & 4.7 & 8.6 \\
\hline LMG $23823^{\mathrm{T}}$ & 8.0 & 5.3 & 6.5 & 8.4 \\
\hline OCC 2758 & 6.5 & 8.0 & 8.0 & 8.3 \\
\hline OCC 118 & 6.9 & 5.2 & 8.3 & 8.8 \\
\hline ATCC $51329^{\mathrm{T}}$ & 8.4 & 6.7 & 7.5 & 8.9 \\
\hline E604 & 6.9 & 5.8 & 6.9 & 7.8 \\
\hline E632 & 6.4 & 5.0 & 7.7 & 7.1 \\
\hline NCTC 9529 & 6.3 & 5.7 & 5.7 & 6.7 \\
\hline LMG $23826^{\mathrm{T}}$ & 6.4 & 4.3 & 6.6 & 5.1 \\
\hline LMG $23827^{\mathrm{T}}$ & 6.9 & 5.7 & 5.7 & 7.2 \\
\hline E934 & 0.0 & 2.9 & 8.3 & 5.1 \\
\hline Mean $\log _{10}$ & 6.3 & 5.0 & 6.9 & 7.5 \\
\hline
\end{tabular}

${ }^{\text {a }}$ ISO 21528 without EE broth.

b BPW plus $10 \mathrm{mg} \mathrm{L}^{-1}$ vancomycin.

BPW plus $40 \mu \mathrm{M}$ 8-hydroxyquinoline plus $0.5 \mathrm{~g} \mathrm{~L}^{-1}$ ammonium iron(III) citrate plus $0.1 \mathrm{~g} \mathrm{~L}^{-1}$ sodium deoxycholate plus $0.1 \mathrm{~g} \mathrm{~L}^{-1}$ sodium pyruvate.
Table 3

Recovery of endogenous Enterobacteriaceae strains from real samples.

\begin{tabular}{lrrrr}
\hline Matrix & No of & \multicolumn{2}{l}{ No. of positive samples } & \\
\cline { 3 - 5 } & samples & ISO 21528 & ${\text { Short } \text { method }^{\mathrm{a}}}$ & BPW-S $^{\mathrm{b}}$ \\
\hline Baby foods & 15 & 0 & 0 & 0 \\
Cocoa powders & 12 & 6 & 6 & 6 \\
Confectionery & 9 & 9 & 9 & 9 \\
Environmental samples & 45 & 36 & 34 & 39 \\
Flour, starch, semolina, or grain & 39 & 31 & 30 & 34 \\
Fruit powders & 6 & 0 & 0 & 0 \\
Infant formula products & 87 & 4 & 2 & 8 \\
Malt drinks & 15 & 0 & 0 & 0 \\
Milk protein & 12 & 2 & 3 & 5 \\
Roasted nuts & 3 & 3 & 3 & 0 \\
Sugars and syrups & 27 & 0 & 0 & 0 \\
Vanilla flavouring & 3 & 0 & 0 & 2 \\
Vegetable powders & 12 & 0 & 0 & 0 \\
Vitamin/mineral mixes & 6 & 0 & 0 & 106 \\
Total & 291 & 91 & 87 & \\
\hline
\end{tabular}

a ISO 21528 without EE broth.

b BPW plus $40 \mu \mathrm{M}$ 8-hydroxyquinoline plus $0.5 \mathrm{~g} \mathrm{~L}^{-1}$ ammonium iron(III) citrate plus $0.1 \mathrm{~g} \mathrm{~L}^{-1}$ sodium deoxycholate plus $0.1 \mathrm{~g} \mathrm{~L}^{-1}$ sodium pyruvate.

strains, such as BcHP, increasing the growth of target strains such as E632 in milk powder. This may be due to metabolism of the media by BcHP, releasing components otherwise unavailable to E632 or to degradation of inhibitory substances. Growth of all the Bacillus strains on $1 \%$ skimmed milk agar and IFMA agar produced zones of clearing (data not shown). Bacillus spp. and related genera are equipped with a wide variety of genes for metabolic and catabolic processes. They have a range of hydrolytic enzymes that allow them to use macromolecules such as proteins (Chopra and Mathur, 1984; El Mayda et al., 1986; Kalogridou-Vassiliadou, 1992), carbohydrates (Kalogridou-Vassiliadou, 1992) and phospholipids (Drobniewski, 1993; Titball, 1993) as nutrients. Other Gram-positive strains appeared to inhibit growth of E632, either by competing for nutrients or producing inhibitory compounds. Strain Bc14 was identified as Bacillus velezensis, this species has been reported to produce a high amount of surfactant that has antimicrobial properties (RuizGarcía et al., 2005). A reduced growth rate was evident for E632 in the presence of the Bc14 filtrate but not that of BcHP. Interestingly, it was also evident that some Enterobacteriaceae strains, such as ATCC $29544^{\mathrm{T}}$ are able to inhibit the growth of Gram-positive organisms such as Bc14 (data not shown). The exact nature of the inhibitory mechanisms was not investigated in this study, it was concluded that as the composition of background flora is unknown in food samples the appropriate strategy would be to add components to the recovery medium to inhibit the non-target Gram-positive organisms and also to promote the growth of target strains.

It has been shown that addition of vancomycin hydrochloride at $10 \mathrm{mg} \mathrm{L}^{-1}$ during pre-enrichment may increase recovery of Enterobacteriaceae (Joosten et al., 2007). The heat stability of vancomycin hydrochloride was investigated and although a reduction in activity was evident after autoclaving at $121^{\circ} \mathrm{C}$ and $115^{\circ} \mathrm{C}$ for $15 \mathrm{~min}$, the Gram-positive strains were inhibited by preparations containing $10 \mathrm{mg} \mathrm{L}^{-1}$. However, the cost, and concerns regarding the possible spread of vancomycin resistance genes (Willems et al., 2005), still mean viable alternative additives to vancomycin are desirable. Therefore we investigated the use of 8-hydroxyquinoline and sodium deoxycholate to inhibit Gram-positive organism during pre-enrichment of Enterobacteriaceae.

Sodium deoxycholate is the selective agent in bile salts and is commonly used in culture media for selection of Gram-negative organisms. The lipophilic nature of the 8-hydroxyquinoline-iron complex allows it to diffuse through cell membranes, however its precise mode of anti-bacterial action is as yet unproven. It has been 
suggested that 8-hydroxyquinoline transiently inhibits growth of Escherichia coli by chelating metal cations that are essential for RNA polymerase to function (Collins et al., 1979). This seems unlikely in view of the fact that 8-hydroxyquinoline induces expression of manganese containing superoxide dismutase (MnSOD) in E. coli (Pugh and Fridovich, 1985). It has been found that exposure to 8-hydroxyquinoline-iron complex caused extreme DNA strand breakage as well as formation of substantial lipid peroxidation products in cultured lung cells (Leanderson and Tagesson, 1996). Iron promotes lipid peroxidation by increasing the formation of oxygen radicals. Cellular levels of iron in the lung cells were threefold higher after exposure to 8-hydroxyquinoline-iron than to other iron chelates and the cellular concentration of malondialdehyde (a marker for oxidative stress) increased four-fold. The 8-hydroxyquinoline-iron complex may generate superoxide anions and possibly acts as a chemical nuclease inducing site-specific breaks by oxidatively degrading the deoxyribose moiety (Leanderson and Tagesson, 1996). In this study co-addition of ammonium iron(III) citrate appeared to be important to facilitate the antimicrobial action of 8-hydroxyquinoline in skimmed milk powder. Supplementation with ammonium iron(III) citrate also had the dual effect of improving recovery of some Enterobacteriaceae strains. This may be due to lack of sufficient free iron in the milk powder, possibly due to sequestration by lactoferrin. Addition of iron(III) ions may saturate iron binding proteins in the milk and provide available free iron for microbial growth. Infant formula powders are routinely supplemented with iron, usually at a concentration of 4.0-12 $\mathrm{mg} \mathrm{L}^{-1}$ as is recommended to reduce the prevalence of irondeficiency anaemia (American Academy of Pediatrics, 1999). Therefore the addition of ammonium iron(III) citrate to infant formula was not essential to the antimicrobial action of 8-hydroxyquinoline and did not increase the growth of Enterobacteriaceae. However, the additional iron in BPW-S did not appear to be detrimental to growth of Enterobacteriaceae or to the inhibition of Grampositive organisms. It can therefore be concluded that a universal supplementation of BPW with iron can be used for both low and high iron-containing samples.

A combination of both sodium deoxycholate and 8-hydroxyquinoline provided the most effective inhibition of the range of Gram-positive organisms tested. However, addition of ammonium iron(III) citrate and sodium pyruvate, which protects desiccation stressed bacteria from peroxide ions (McDonald et al., 1983), was necessary to improve recovery of desiccation stressed Enterobacteriaceae. The optimal enrichment broth in this study was determined to be BPW supplemented with $40 \mu \mathrm{M}$ 8-hydroxyquinoline, $0.5 \mathrm{~g} \mathrm{~L}^{-1}$ ammonium iron(III) citrate, $0.1 \mathrm{~g} \mathrm{~L}^{-1}$ sodium deoxycholate and $0.1 \mathrm{~g} \mathrm{~L}^{-1}$ sodium pyruvate (BPW-S). This medium gave consistently greater final concentrations of target cells when skimmed milk powder was artificially contaminated with low levels of lyophilised Enterobacteriaceae cells. The composition of pre-enrichment broth is modified by addition of the sample at a 1:10 ratio and matrix components may change the inhibitory (and growth promoting) properties of the homogenate. However, the results in Table 3 show that BPW-S seems to be suitable for a variety of matrices as this method also detected endogenous Enterobacteriaceae in significantly more samples of the naturally contaminated food and environmental matrixes tested than did the ISO 21528-1:2004 or the shortened method.

Improvements to the composition of BPW with a view to inhibition of competing Gram-positive background flora may potentially improve recovery of Gram-negative organisms from samples. This method may have useful application as a pre-enrichment step in other microbiological culture methods for recovery of Gram-negative pathogens, such as Salmonella and Cronobacter, as well as indicator organisms.

\section{Acknowledgements}

The authors are grateful to Hochdorf Nutritec AG and Kraft Foods for provision of field samples and to James Beaves, Thermofisher, for preparation of the spray-dried cultures.

\section{References}

Albert, A., Rubbo, S., Goldacre, R., Balfour, B., 1947. A study of 8-hydroxyquinoline and related compounds. Br. J. Exp. Pathol. 28, 69-87.

American Academy of Pediatrics, Committee on Nutrition, 1999. Iron fortification of infant formulas. Pediatrics 104, 119-123.

Anderton, A., 1986. Microbiological quality of products used in enteral feeds. J. Hosp. Infect. 7, 68-73.

Anon., 2004. ISO 21528-1:2004, Microbiology of food and animal feeding stuffs horizontal methods for the detection and enumeration of Enterobacteriaceae - Part 1: Detection and enumeration by MPN technique with pre-enrichment.

Anon., 2005. Commission Regulation (EC) No 2073/2005 of 15 November 2005 on microbiological criteria for foodstuffs. http://www.eurlex.europa.eu/ LexUriServ/LexUriServ.do?uri=CONSLEG:2005R2073:20060101:EN:PDF.

Antai, S.P., 1988. Study of the Bacillus flora of Nigerian spices. Int. J. Food Microbiol. 6, 259-261.

Chopra, A.K., Mathur, D.K., 1984. Isolation, screening and characterization of thermophilic Bacillus species isolated from dairy products. J. Appl. Bacteriol. 57, 263-271.

Collins, J.J., Alder, C.R., Fernandez-Pol, J.A., Court, D., Johnson, G.S., 1979. Transient growth inhibition of Escherichia coli K-12 by iron chelators: in vivo inhibition of ribonucleic acid synthesis. J. Bacteriol. 138, 923-932.

Crielly, E.M., Logan, N.A., Anderton, A., 1994. Studies on the Bacillus flora of milk and milk products. J. Appl. Bacteriol. 77, 256-263.

D’Mello, A., Yotis, W.W., 1987. The action of sodium deoxycholate on Escherichia coli. Appl. Environ. Microbiol. 53, 1944-1946.

Depalma, P.D., Loux, J.J., Hutchman, J., Dolan, M.M., Yankell, S.L., 1975. Anticalculus and antiplaque activity of 8-hydroxyquinoline sulfate. J. Dent. Res. 55, 292-298.

Drobniewski, F.A., 1993. Bacillus cereus and related species. Clin. Microbiol. Rev. 6, 324-338.

El Mayda, E., Pâquet, D., Ramet, J.P., Linden, G., 1986. Proteolytic activity of a Bacillus subtilis neutral protease preparation upon caseins and whey proteins of cow's milk. J. Dairy Sci. 69, 305-310.

Gabis, D.A., Langlois, B.E., Rudnick, A.W., 1970. Microbiological examination of cocoa powder. Appl. Microbiol. 20, 644-645.

Gurtler, J.B., Beuchat, L.R., 2005. Performance of media for recovering stressed cells of Enterobacter sakazakii as determined using spiral plating and ecometric techniques. Appl. Environ. Microbiol. 71, 7661-7669.

Haselwood, G.A.D., 1967. Bile salt evolution. J. Lipid Res. 8, 535-550.

He, Z., Kisla, D., Zhang, L., Yuan, C., Green-Church, K.B., Yousef, A.E., 2007. Isolation and identification of a Paenibacillus polymyxa strain that coproduces a novel lantibiotic and polymyxin. Appl. Environ. Microbiol. 73, 168-178.

Huck, J.R., Sonnen, M., Boor, K.J., 2008. Tracking heat-resistant, cold-thriving fluid milk spoilage bacteria from farm to packaged product. J. Dairy Sci. 91, 1218-1228.

Iversen, C., Forsythe, S., 2007. Comparison of media for the isolation of Enterobacter sakazakii. Appl. Environ. Microbiol. 73, 48-52.

Joosten, H., Iversen, C., Jackson, T., Marugg, J., Stephan, R., 2007. P39-A shortened method for the detection of Enterobacteriaceae. IAFP's Third European Symposium on Food Safety: Advancements in Food Safety. Rome, Italy, 18-19 October 2007.

Joosten, H., Marugg, J., Stephan, R., Klijn, A., Jackson, T., Iversen, C., 2008. A rapid and reliable alternative to ISO 21528-1:2004 for detection of Enterobacteriaceae. Int. J. Food Microbiol. 125, 344-346.

Kalogridou-Vassiliadou, D., 1992. Biochemical activities of Bacillus species isolated from flat sour evaporated milk. J. Dairy Sci. 75, 2681-2686.

Katz, E., Demain, A.L., 1977. The peptide antibiotics of Bacillus: chemistry, biogenesis, and possible functions. Microbiol. Mol. Biol. Rev. 41, 449-474.

Kunene, N.F., Hastings, J.W., von Holy, A., 1999. Bacterial populations associated with a sorghum-based fermented weaning cereal. Int. J. Food Microbiol. 49, 75-83.

Leanderson, P., Tagesson, C., 1996. Iron bound to the lipophillic iron chelator; 8-hydroxyquinoline, causes DNA strand breaks in cultured lung cells. Carcinogenesis 17, 545-550.

MacConkey, A.T., 1905. Lactose-fermenting bacteria in faeces. J. Hyg. 5, 333-379.

McDonald, I.C., Hackney, C.R., Ray, B., 1983. Enhanced recovery of injured Escherichia coli by compounds that degrade hydrogen peroxide or block its formation. Appl. Environ. Microbiol. 45, 360-365.

Miles, A.A., Misra, S.S., Irwin, J.O., 1938. The estimation of the bactericidal power of the blood. J. Hyg. (Cambridge) 38, 732-749.

Murphy, P.M., Lynch, D., Kelly, P.M., 1999. Growth of thermophilic spore forming bacilli in milk during the manufacture of low heat powders. Int. J. Dairy Technol. 52, 45-50.

Nicholson, W.L., Munakata, N., Horneck, G., Melosh, H.J., Setlow, P., 2000. Resistance of Bacillus endospores to extreme terrestrial and extraterrestrial environments. Microbiol. Mol. Biol. Rev. 64, 548-572. 
Pugh, S.Y.R., Fridovich, I., 1985. Induction of superoxide dismutases in Escherichia coli B by metal chelators. J. Bacteriol. 162, 196-202.

Reyes, J.E., Bastías, J.M., Gutiérrez, M.R., Rodríguez, M.O., 2007. Prevalence of Bacillus cereus in dried milk products used by Chilean School Feeding Program. Food Microbiol. 24, 1-6.

Ronimus, R.S., Rueckert, A., Morgan, H.W., 2006. Survival of thermophilic sporeforming bacteria in a $90+$ year old milk powder from Ernest Shackelton's Cape Royds hut in Antarctica. J. Dairy Res. 73, 235-243.

Rueckert, A., Ronimus, R.S., Morgan, H.W., 2005. Development of a rapid detection and enumeration method for thermophilic bacilli in milk powders. J. Microbiol. Methods 60, 155-167.

Ruiz-García, C., Béjar, V., Martínez-Checa, F., Llamas, I., Quesada, E., 2005. Bacillus velezensis sp. nov., a surfactant producing bacterium isolated from the river Vélez in Málaga, southern Spain. Int. J. Syst. Evol. Microbiol. 55, 191-195.
Stacey, M., Webb, M., 1947. Studies on the antibacterial properties of the bile acids and some compounds derived from cholanic acid. Proc. Roy. Soc. London Series B, Biol. Sci. 134, 523-537.

Stock, I., Wiedemann, B., 2002. Natural antibiotic susceptibility of Enterobacter amnigenus, Enterobacter cancerogenus, Enterobacter gergoviae and Enterobacter sakazakii strains. Clin. Microbiol. Infect. 8, 564-578.

Tanzer, J.M., Slee, A.M., Kamay, B., Scheer, E., 1978. Activity of three 8-hydroxyquinoline derivatives against in vitro dental plaque. Antimicrobial Agents Chemother. 13, 1044-1045.

Titball, R.W., 1993. Bacterial phospholipases C. Microbiol. Rev. 57, 347-366.

Willems, R.J., Top, J., van Santen, M., Robinson, D.A., Coque, T.M., Baquero, F., Grundmann, H., Bonton, M.J., 2005. Global spread of vancomycin-resistant Enterococcus faecium form distinct nosocomial genetic complex. Emerg. Infect. Dis. $11,821-828$. 